\title{
Derecho a la privacidad, libertad de expresión e interés público: el caso Cordero con Lara y otros
}

\section{Right to Privacy, freedom of expression and public interest: the Cordero $v$. Lara et al. case}

\author{
Camilo Jara Villalobos \\ Universidad de Chile, Chile
}

Abogado de la Universidad de Chile. Ayudante ad-honorem de la cátedra de Clínica de Justicia Constitucional de la misma casa de estudios. Finalista del concurso de tesis 2013 del Instituto Nacional de Derechos Humanos con el trabajo titulado "El Derecho de Acceder a la Información Pública: Vías de Intervención Ciudadana". Autor de varias publicaciones y columnas sobre transparencia y acceso a la información pública. Actualmente se desempeña como pasante de investigación en el Centro de Estudios de Justicia de las Américas (CEJA), en Santiago de Chile.

cjarav@ug.uchile.cl

\section{RESUMEN}

En agosto de 2013, la Corte Suprema de Chile debió resolver un caso criminal por el delito de violación a la privacidad. El caso versaba sobre una psiquiatra que había sido grabada secretamente por un programa televisión otorgando licencias médicas de manera irregular. En su resolución, la Corte Suprema abandonó su criterio tradicional referido a la primacía del derecho a la privacidad y señaló que cuando hay un interés público comprometido, este cede en beneficio del derecho que tienen los ciudadanos a conocer la información. El presente artículo analiza los conceptos de privacidad, libertad de expresión y acceso a la información y su desarrollo normativo y jurisprudencial en el derecho internacional de los derechos humanos y en Chile, resaltando la importancia de la sentencia comentada para la protección de la libertad de expresión y el interés público.

Palabras clave: Derecho a la privacidad - libertad de expresión- acceso a la información- interés público.

\begin{abstract}
In August, 2013, the Supreme Court of Chile decided a criminal case regarding violation of privacy. The case was about a psychiatrist that had been secretly recorded by a television show issuing false medical leaves. In its decision, the Supreme Court abandoned the traditional supremacy of the right to privacy pointing out that when there is a public interest at stake, the former should be disregarded for the benefit of citizens to know the truth. This article analyses concepts such us privacy, freedom of expression and access to information, as well as their normative and jurisprudential development within Humans Rights practice in a national context. It also emphasizes that this decision is cornerstone for the protection of the freedom of expression and the public interest.
\end{abstract}

Key words: Right to privacy - freedom of expression - access to information - public interest. 


\section{Introducción}

En agosto de 2013, a raíz de un caso criminal por uso de cámaras ocultas al interior de una consulta médica, la Corte Suprema de Chile debió pronunciarse acerca de los límites del derecho a la privacidad en relación con el derecho a la libertad de expresión, en el denominado caso Cordero con Lara y otros ${ }^{1}$.

Este caso resulta interesante, pues la Corte Suprema no solo realizó un análisis del tipo penal invocado y su calificación jurídica, sino que desarrolló el concepto de derecho a la intimidad y, por primera vez, estableció como límite a este derecho fundamental, la existencia de un interés público comprometido en la divulgación de la información obtenida. De esta forma, la Corte Suprema recogió un criterio asentado en la jurisprudencia comparada y en el Derecho Internacional de los Derechos Humanos (DIDH).

Este artículo se propone analizar brevemente los conceptos de derecho a la privacidad, libertad de expresión y, particularmente, el concepto de interés público en el ordenamiento jurídico chileno y su desarrollo en el DIDH. Asimismo, se revisará el desarrollo que la Corte Suprema hace de estos conceptos en el caso Cordero con Lara y otros, y la innovación que representa este fallo para la consolidación del criterio del interés público como límite del derecho a la privacidad y como fundamento para la divulgación de información.

\section{Derecho a la privacidad, libertad de expresión y acceso a la información}

A nivel regional, la Convención Americana sobre Derechos Humanos (CADH) establece en su artículo 11.2 el derecho a la privacidad, señalando que "nadie puede ser objeto de injerencias arbitrarias o abusivas en su vida privada, en la de su familia, en su domicilio o en su correspondencia, ni de ataques ilegales a su honra o reputación". Sobre el alcance de este derecho, la Corte Interamericana de Derechos Humanos (Corte IDH) ha indicado que "el ámbito de la privacidad, se caracteriza por quedar exento e inmune a las invasiones o agresiones abusivas o arbitrarias por parte de terceros o de la autoridad pública" ${ }^{2}$. Asimismo, ha señalado que la protección de la vida privada alcanza las comunicaciones en un sentido amplio, incluyendo las formas tecnológicas, como por ejemplo, las conversaciones telefónicas 3 .

En Chile, la doctrina entiende la privacidad como un atributo de la persona humana ${ }^{4}$, consistente en los "asuntos, conductas, documentos, comunicaciones, imágenes o recintos que el titular del bien jurídico protegido no desea que sean conocidos sin su consentimiento previo" ${ }^{\prime \prime}$. En otras palabras, el concepto de privacidad se refiere a aquella parte de nuestras vidas que no queda al escrutinio público. La Constitución chilena contempla expresamente la privacidad como garantía constitucional en el artículo 19 No. 4. Este establece que "el Estado garantiza a todas las personas: el respeto y protección a la vida privada y a la honra de la persona y su familia". Como consecuencia de la regulación conjunta de dos derechos fundamentales, históricamente

Corte Suprema de Chile. Sentencia de 21 de agosto de 2013. Rol 8393-2012.

Corte IDH. Caso de las Masacres de Ituango vs. Colombia. Excepciones Preliminares, Fondo, Reparaciones y Costas. Sentencia de 1 de julio de 2006. Serie C No. 148, párr.194.

Corte IDH. Caso Tristán Donoso vs. Panamá. Excepción Preliminar, Fondo, Reparaciones y Costas. Sentencia del 29 de enero de 2009. Serie C No. 193, párr. 55.

DuCCI, Carlos. Derecho Civil: Parte General. Santiago: Editorial Jurídica de Chile, 1994, p.154.

CEA EGAÑA, José Luis. Derecho Constitucional Chileno: Derechos, Deberes y Garantías, Tomo II. Santiago: Ediciones Universidad Católica de Chile, 2004, p.178. 
se ha relacionado la intimidad con la honra, el honor y el prestigio de las personas ${ }^{6}$, lo que se ha manifestado en la jurisprudencia derivada de acciones constitucionales de protección ${ }^{7}$.

Tradicionalmente -con excepción de algunos votos de minoría ${ }^{8}$ - los tribunales superiores de justicia chilenos han optado por cautelar las amenazas al honor e intimidad por sobre la libertad de expresión e información ${ }^{9}$, no aceptándose criterios de legitimación tales como el interés público $^{10}$ en divulgar la información, así como tampoco se ha cautelado la exceptio veritatis en el caso de la prensa ${ }^{11}$, como ha ocurrido por ejemplo, en casos criminales por delito de injurias $^{12}$.

Por otra parte, el derecho a la libertad de expresión abarca la posibilidad de difundir toda clase de ideas, pensamientos, creaciones literarias, artísticas, científicas, técnicas o de cátedra ${ }^{13}$, e incluye "la posibilidad de profesar y discutir, como una cuestión ética, cualquier doctrina, por inmoral que pudiera considerarse ${ }^{\prime 14}$. La CADH lo consagra en su artículo 13 en los siguientes términos: "toda persona tiene derecho a la libertad de pensamiento y de expresión. Este derecho comprende la libertad de buscar, recibir y difundir informaciones e ideas de toda índole, sin consideración de fronteras, ya sea oralmente, por escrito o en forma impresa o artística, o por cualquier otro procedimiento de su elección".

El derecho de acceder a la información pública se considera como implícito dentro del derecho a la libertad de expresión, en el sentido de que la condición de la posibilidad de expresarse o informar, es que exista la posibilidad de acceder a la información" ${ }^{15}$. Se entiende como "el derecho de todas las personas de preguntar a las autoridades públicas por la información que

HUEPE, Felipe. "El acceso a la información y el secreto o reserva fundado en el derecho a la privacidad". En: LETELIER, Raúl y RAJEVIC, Enrique (Eds.). Transparencia en la administración pública. Santiago: Abeledo Perrot, 2010, p.340.

ANGUITA, Pedro. "Jurisprudencia constitucional sobre el derecho a la propia imagen y a la vida privada en Chile (1981-2004): un intento de sistematización". En: GONZÁLEZ, Felipe (Ed.). Libertad de expresión en Chile. Santiago: Facultad de Derecho Universidad Diego Portales, 2006, p. 327.

A modo de ejemplo, es ilustrativo el voto de minoría del Ministro Sergio Muñoz -actual Presidente de la Corte Suprema- en el caso de la acción de protección contra el libro "Cecilia, la vida en Ilamas". En el voto, el Ministro señaló que "[...] en una sociedad democrática, en que rigen plenamente las libertades y se asegura la dignidad de todos los individuos, en un debate libre y sin censura previa, cuando se trata de personas de interés público pueden ser inevitables los errores, especialmente cuando tales personas han querido dejar ciertos hechos preservados del conocimiento público radicándolos dentro de su natural derecho a la intimidad, por ello se dispone por el Estado de los mecanismos pertinentes de reparación y represión de tales excesos en forma posterior, en lo cual, sin embargo, debe preferirse siempre de aquellos medios que no limiten los derechos de terceros e incluso del mismo imputado". Corte de Apelaciones de Santiago. Sentencia de 13 de enero de 2003. Rol 63135-2003. Voto de minoría, considerando 4. GRISOLÍA, Francisco. Libertad de Expresión y Derecho a la Honra. Santiago: Editorial Lexis Nexis, 2004, p.223.

EVA, María José. "Fallo Páez con Barahona: libertad de expresión e interés público". Anuario de Derechos Humanos, No.1, 2005, p.151. ANGUITA, Pedro. Jurisprudencia constitucional... op. cit., p.328.

Ejemplo de aquello es el caso "Páez con Barahona" (Corte Suprema de Chile. Sentencia de 9 de septiembre de 2004. RUC 0410008047-3) y aquellos casos de prohibiciones judiciales de circulación de libros, tales como "Impunidad Diplomática" a comienzos de la década de los 90' (Corte Suprema de Chile. Sentencia de 15 de junio de 1993. Rol 21053-1993) y "Cecilia, Vida en Llamas" una década después (Corte de Apelaciones de Santiago. Sentencia de 4 de febrero de 2004. Rol 63135-2003).

HUEPE, Felipe. El acceso a la información... op. cit., p. 333.

14 MILL, John. On Liberty and other Essays. Oxford World's Classics. Nueva York: Oxford University Press, 1998, p.14.

HUEPE, Felipe. El acceso a la información... op. cit., p. 333. 
están haciendo y los documentos que tienen y el derecho a recibir una respuesta"16. La Corte IDH lo ha conceptualizado estableciendo que "al estipularse expresamente los derechos a 'buscar' y a 'recibir' 'informaciones', se protege el derecho que tiene toda persona a solicitar el acceso a la información bajo el control del Estado, con las salvedades permitidas bajo el régimen de restricciones de la Convención. Consecuentemente, dicho artículo ampara el derecho de las personas a recibir dicha información y la obligación positiva del Estado de suministrarla"17.

En el caso chileno, la Constitución garantiza a todas las personas en su artículo 19 No.12 "la libertad de emitir opinión y la de informar, sin censura previa, en cualquier forma y por cualquier medio, sin perjuicio de responder de los delitos y abusos que se cometan en el ejercicio de estas libertades, en conformidad a la ley". En relación a lo anterior, el Tribunal Constitucional ha señalado que "el derecho a acceder a las informaciones que obran en poder de los órganos del Estado forma parte de la libertad de expresión que, entre nosotros, se encuentra consagrada en el artículo 19 No. 12 de la Carta Fundamental [...]. Este mismo Tribunal ha sostenido que la libertad de informar incluye el derecho a recibir informaciones"18.

Es importante resaltar que ambos derechos -libertad de expresión y acceso a la informaciónson "dos caras que se conjugan para crear una capacidad intelectual en la ciudadanía, que es la capacidad de hacer juicios certeros sobre la realidad y, por lo tanto, el primer paso para solucionar los problemas"19. Se espera que una sociedad activa e informada esté en mejores condiciones de participar en la toma de decisiones, controlar el actuar público, e incidir para el respeto de los derechos fundamentales ${ }^{20}$.

\title{
2. Conflicto entre el derecho a la privacidad, libertad de expresión y acceso a la información: el interés público como límite
}

En la colisión entre el derecho a la privacidad y la libertad de expresión, el conflicto se puede generar porque una persona puede informar o comunicar al público aspectos de la vida privada del otro/a sin su consentimiento. Para resolver estos conflictos, la Corte IDH ha indicado los requisitos para determinar cuándo es legítima una restricción del derecho a la privacidad en pos de la libertad de expresión y acceso a la información, señalando que:

\begin{abstract}
[...] las restricciones que se impongan deben ser necesarias en una sociedad democrática, lo que depende de que estén orientadas a satisfacer un interés público imperativo. Entre varias opciones para alcanzar ese objetivo, debe escogerse aquélla que restrinja en menor escala el derecho protegido. Es decir, la restricción debe ser proporcional al interés que la justifica y debe ser conducente para alcanzar el logro de ese legítimo objetivo, interfiriendo en la menor
\end{abstract}

16 Access Info. The Aid Transparency Toolkit, 2009, p.6. Disponible [en línea] <http://www.access-info.org/documents/files/The_Aid_Transparency_Toolkit_-_Access_Info_22_October_2009.pdf> [consulta: 31 de octubre $2013]$.

17 Corte IDH. Caso Claude Reyes y otros vs. Chile. Fondo, Reparaciones y Costas. Sentencia del 19 de septiembre de 2006. Serie C No. 151, párr. 77.

18 Tribunal Constitucional de la República de Chile. Sentencia de 9 de agosto de 2007. Rol 634-2006-INA, considerando 9. Desde 2009, el derecho de acceder a la información está expresamente regulado en la Ley No. 20.285 de Transparencia y Acceso a la Información Pública, que permite a los ciudadanos realizar solicitudes de información, y en caso de negativa por parte de los organismos públicos, impugnar la decisión ante el Consejo para la Transparencia.

19 CONTRERAS, Pablo y GARCÍA, Gonzalo. "Derecho de acceso a la información en Chile: nueva regulación e implicancias para el sector de la defensa nacional". Revista de Estudios Constitucionales, año 7, No. 1, 2009 , p. 142.

Instituto Nacional de Derechos Humanos. Derechos Humanos y Acceso a la Información Pública. Serie Cuadernillos de Temas Emergentes, 2012, p. 8. Disponible [en línea] <http://bibliotecadigital.indh.cl/bitstream/handle/123456789/315/info-publica.pdf?sequence=1> [consulta: 31 octubre 2013]. 
medida posible en el efectivo ejercicio del derecho ${ }^{21}$.

En este sentido, resulta legítimo restringir la privacidad, en la medida en que se pruebe que existe un interés público en que la ciudadanía conozca una determinada información, y que haya proporcionalidad entre la relevancia de divulgar los antecedentes y el nivel de afectación a la intimidad. Por tanto, el determinar qué se entiende por interés público resulta fundamental para analizar la legitimidad de las restricciones al derecho a la privacidad.

En relación al concepto de interés público, se postula que la "tutela de la vida privada de una persona está dada en una proporción inversa a su participación en cuestiones públicas, cualquiera sea el ámbito de donde se proyecte a la sociedad"22. En este sentido, se han desarrollado por la doctrina tres categorías de personas ${ }^{23}$ : los "oficiales públicos" -aquellos que detentan la calidad de servidores del Estado-, las Ilamadas "personas públicas" -aquellas personas que aunque no son funcionarios tienen la capacidad de influir en los asuntos públicos - y las "personas privadas", que son aquellas que no se comprenden en las categorías anteriores. En relación a las dos primeras categorías, tanto la doctrina como jurisprudencia comparada han entendido que -dada la relevancia pública de las personas en cuestión-, existe un interés público sobre la información relativa a ellas ${ }^{24}$.

Este concepto de interés público, relacionado con el derecho de acceso a la información y como límite al derecho a la privacidad, ha sido desarrollado en la jurisprudencia de la Corte IDH:

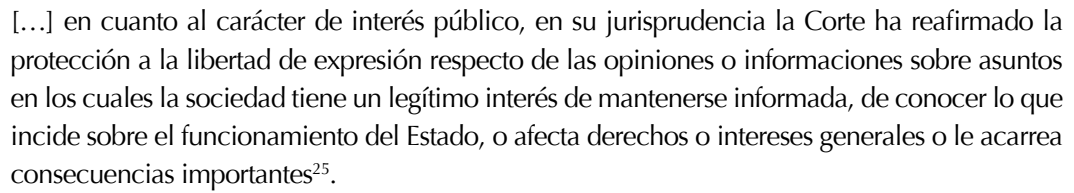

En este sentido, en concepto de la Corte IDH, para que estemos en presencia de un interés público comprometido en la divulgación de determinada información, se requiere que esta verse sobre el funcionamiento del Estado -lo cual incluye el comportamiento de sus oficiales o funcionarios-, que los datos versen sobre derechos o intereses de carácter general, o que les pueda acarrear consecuencias importantes a la sociedad.

Resulta interesante destacar que el concepto de interés público no es sinónimo de interés estatal, sino que está relacionado a lo "público" en un sentido amplio, "lo que comprende lo estatal y lo no estatal, esto es, que abarca las manifestaciones de la sociedad civil y de la participación

\footnotetext{
21 Corte IDH. Caso Claude Reyes y otros vs. Chile. Fondo, Reparaciones y Costas. Sentencia de 19 de septiembre de 2006. Serie C No. 151, párr. 91.

22 ANGUITA, Pedro. Jurisprudencia constitucional... op. cit., p. 341.

23 GARCÍA, Luis. Estudios sobre el Derecho a la Intimidad. Madrid: Editorial Tecnos, 1992, p. 22.

24 CASTRO, Montserrat y MUÑOZ, Ana María. "Acceso a la información pública y autodeterminación informativa: publicidad de las remuneraciones de los altos ejecutivos de las empresas públicas: el caso TVN". Revista Chilena de Derecho y Tecnología, No.1, 2012, p. 161.
}

25 Corte IDH. Caso Fontevecchia y D'Amico vs. Argentina. Fondo, Reparaciones y Costas. Sentencia de 29 de noviembre de 2011. Serie C No. 238, párr.61. En similar sentido puede verse: caso Ricardo Canese vs. Paraguay. Fondo, Reparaciones y Costas. Sentencia del 31 de agosto de 2004. Serie C No. 111, párr. 98; caso Kimel vs. Argentina. Fondo, Reparaciones y Costas. Sentencia del 2 de mayo de 2008. Serie C No. 177, párr. 86 y; caso Tristán Donoso vs. Panamá. Excepción Preliminar, Fondo, Reparaciones y Costas. Sentencia del 27 de enero de 2009. Serie C No. 193, párr. 115. 
ciudadana" 26 .

Sin embargo, recientemente, la Corte IDH en el caso Mémoli vs. Argentina -que versa sobre la condena por difamación a un periodista por denunciar un presunto delito de estafa de venta de tumbas en un cementerio argentino-, restringió la definición que había desarrollado en su jurisprudencia constante, estableciendo que como las víctimas de la supuesta estafa denunciada eran los miembros de una organización privada, y que como los denunciados por el periodista habían sido absueltos por los tribunales argentinos, no se podía verificar la presencia de un interés público comprometido.

\section{La Corte IDH señaló al respecto que:}

[...] A diferencia de otros casos resueltos por esta Corte, en el presente caso las expresiones por las cuales fueron condenados los señores Mémoli no involucraban a funcionarios o figuras públicas ni versaban sobre el funcionamiento de las instituciones del Estado. Por el contrario, este Tribunal nota que las denuncias y expresiones por las cuales fueron condenados los señores Mémoli [periodistas] se habrían producido en el contexto de un conflicto entre personas particulares sobre asuntos que, eventualmente, solo afectarían a los miembros de una Asociación Mutual de carácter privado, sin que conste que el contenido de dicha información tuviera una relevancia o impacto tal como para trascender a la sola Asociación y ser de notorio interés para el resto de la población [...] por el contrario, consta en autos que la denuncia por estafa presentada por los señores Mémoli por el 'caso de los nichos' fue examinada por la justicia y que el 6 de junio de 1990 el Juez encargado de la denuncia sobreseyó la causa ${ }^{27}$.

De esta forma, concluye que de los hechos del caso no se desprende que la información contenida en las expresiones de los señores Mémoli sea de interés público ${ }^{28}$.

\section{El interés público en Chile}

Hasta agosto de 2013, el criterio del interés público como limitación del derecho a la privacidad y legitimador de los derechos de la información no había sido aceptado por la Corte Suprema y, consecuentemente, no existía un concepto jurisprudencial al respecto ${ }^{29}$.

El único pronunciamiento sobre el tema lo había realizado el Tribunal Constitucional en el año 2011. El organismo, de manera sucinta -con ocasión de una solicitud del canal estatal Televisión Nacional de Chile destinada a evitar la publicación de las remuneraciones de la plana directiva de la empresa-, señaló que en relación al uso de los recursos estatales, existiría un innegable interés público en conocer las remuneraciones de los funcionarios del Estado ${ }^{30}$. El concepto de

GONZÁLEZ, Felipe. "Presentación". En: GONZÁLEZ, Felipe (Ed.). Derechos Humanos e Interés Público. Cuadernos de Análisis Jurídico No. 11, Serie de Publicaciones Especiales. Santiago: Universidad Diego Portales, 2001, p. 7.

Corte IDH. Caso Mémoli vs. Argentina. Excepciones Preliminares, Fondo, Reparaciones y Costas. Sentencia del 22 de agosto de 2013. Serie C No. 265, párr. 146.

Ibídem, párr. 147.

El interés público había sido alegado ante las Cortes sin éxito, por ejemplo, en casos como en el amparo contra el auto de procesamiento en "Guillier con Pérez" (caso del Juez Calvo), rechazado por la Corte Suprema en sentencia del 22 de diciembre de 2003, rol 33865-2003.

Sobre el particular, el Tribunal Constitucional dispuso que "en el caso de autos, la aplicación del artículo décimo de la Ley № 20.285 permite dar publicidad al destino de los recursos que las empresas públicas dedican para remunerar a su plana directiva. El conocimiento de tales remuneraciones y el de las que corresponden a los funcionarios del Estado presenta un innegable interés público. En el caso sub lite la publicidad de las remuneraciones de los requirentes se exige en razón del alto cargo que desempeñan en TVN y de la naturaleza de la empresa que 
interés público tampoco está definido expresamente por la legislación, pero sí está presente en dos normas de nuestro ordenamiento jurídico: de manera explícita en la Ley de Prensa, y de forma más o menos implícita en la Ley de Transparencia y Acceso a la Información Pública.

La Ley No.19.733 (Ley de Prensa) ${ }^{31}$, establece en su artículo 30 que al miembro de la prensa inculpado de haber causado injuria a través de un medio de comunicación, no le será admitida prueba de verdad -la exceptio veritatis-, sino cuando la imputación se produjere con motivo de defender un interés público real, debiendo considerarse como hechos de interés público de una persona los siguientes: a) los referentes al desempeño de funciones públicas; b) los realizados en el ejercicio de una profesión u oficio y cuyo conocimiento tenga interés público real; c) los que consistieren en actividades a las cuales haya tenido libre acceso el público, a título gratuito u oneroso; d) las actuaciones que, con el consentimiento del interesado, hubieren sido captadas o difundidas por algún medio de comunicación social; e) los acontecimientos o manifestaciones de que el interesado haya dejado testimonio en registros o archivos públicos y; f) los consistentes en la comisión de delitos o participación culpable en los mismos. Sin embargo, pese a la existencia del interés público en la Ley de Prensa para el delito de injuria cometido por periodistas o medios de comunicación, la evidencia indica que los tribunales con competencia penal no lo habían considerado en sus sentencias ${ }^{32}$.

Asimismo, el concepto de interés público está presente en la Ley No. 20.285 (Ley de Transparencia y Acceso a la Información Pública ${ }^{33}$. Pese a que no está tratado de manera expresa en la Ley, ha sido utilizado reiteradamente como criterio interpretativo por el Consejo para la Transparencia $(\mathrm{CPLT})^{34}$, a través de los denominados "test de daños" y "test de interés público". En efecto, cuando el CPLT tiene que decidir sobre una solicitud de acceso a la información, en la cual se ha requerido información o datos personales y está en juego el derecho a la privacidad u otras causales, se ha entendido que "la ley de transparencia incorporó el test de daño como uno de los criterios para resolver la aplicación de las excepciones al principio de publicidad"35.

El test de daño ha sido conceptualizado por la jurisprudencia del CPLT, y consiste en responder tres preguntas. Se ha señalado (refiriéndose al derecho de acceder a la información) que "establecido que estamos en presencia de un derecho de rango constitucional la reserva o secreto pasa a limitarlo o restringirlo, por lo que debe respetar el principio de proporcionalidad que supone analizar, conforme señala la doctrina: a) si la medida es eficaz, b) si no existe un medio más moderado para la consecución eficaz del propósito buscado [...] y, por último, c) si de la medida a adoptar derivan más beneficios o ventajas para el interés general que perjuicios sobre otros bienes o valores en conflicto" ${ }^{\prime 36}$.

dirigen, no en tanto sujetos particulares corrientes". Tribunal Constitucional de la República de Chile. Sentencia de 21 de junio de 2011. Rol 1732-2010-INA, considerando 34.

31 Ley No.19.733 de 2001 sobre Libertades de Opinión e Información y Ejercicio del Periodismo. Congreso Nacional de la República de Chile, 4 de junio de 2001.

32 LOVERA, Domingo. "El interés público como estándar. Libertad de expresión y vida privada". En: GONZÁLEZ, Felipe (Ed.). Libertad de Expresión en Chile. Santiago: Facultad de Derecho Universidad Diego Portales, 2006, p. 86.

33 Ley No. 20.285 de 2008 sobre Transparencia y Acceso a la Información Pública. Congreso Nacional de la República de Chile, 20 de agosto de 2008.

34 Consejo para la Transparencia. Protección de Datos Personales. Santiago: Unidad de Normativa, Dirección Jurídica CPLT, 2011, p. 32.

35 TELLO, Cristóbal, CERNA, Marcelo y PAVÓN, Andrés. "Acceso a la información pública: los desafíos del Consejo para la Transparencia". Anuario de Derechos Humanos, No. 5, 2009, p. 197. A modo de ejemplo, ver: CPLT. Resolución de 28 de julio de 2009. Rol A-45-2009, considerando 10. 
Por su parte, el test o prueba de interés público ha sido recogido por el CPLT en términos similares al desarrollo jurisprudencial de la Corte IDH, comprendiendo aspectos relacionados al funcionamiento del Estado ${ }^{37}$, derechos o intereses generales y con la capacidad de afectar a parte importante de la población ${ }^{38}$.

\section{El caso Cordero contra Lara y otros}

El caso se inició el año 2003 producto de la investigación del área de prensa del canal de televisión privado "Chilevisión", relacionada con la supuesta entrega por parte de médicos psiquiatras de licencias médicas fraudulentas.

Los periodistas solicitaron ser atendidos por varios médicos especialistas y se presentaron a las consultas de estos simulando ser pacientes, requiriendo directamente a los facultativos el otorgamiento de licencias médicas fraudulentas por trastornos médicos que nunca existieron. De esta forma, obtuvieron licencias médicas de hasta 25 días de descanso. Lo que desconocían los médicos que entregaban las licencias, era que los pacientes trabajaban como profesionales de la prensa e iban premunidos de cámaras ocultas, de manera que grababan íntegramente las conversaciones al interior de las consultas médicas.

Una vez exhibido el reportaje en la televisión, la psiquiatra María Luisa Cordero (aludida en el reportaje) -panelista habitual de programas de televisión y autora de varios libros sobre la actualidad chilena- se querelló por el delito del artículo 161-A del Código Penal ${ }^{39}$, denominado "violación de la privacidad"40, resultando condenados los periodistas y productores del programa, en primera instancia por el $22^{\circ}$ Juzgado del Crimen de Santiago a la pena de 61 días de reclusión, al pago de una multa y a una indemnización por daño moral. La Corte de Apelaciones de Santiago confirmó lo resuelto en primera instancia, por lo que los acusados recurrieron a la Corte Suprema.

Ante el máximo tribunal del país, la defensa de los acusados se basó en objetar la calificación jurídica de los hechos, en razón que no habría existido una intromisión ilegítima en la vida privada; que la conversación médico-paciente se habría desarrollado en un edificio fiscal (como era un hospital de la red pública de salud); y que la conversación no podía tener carácter confidencial pues uno de los participantes -el periodista- no tenía tal ánimo de secreto. Asimismo, el defensor alegó que no pueden tener carácter privado aquellos hechos cuya publicidad envuelva un interés público, ya que de mantenerse oculto el supuesto fraude de las licencias médicas, solo se perpetuaría una situación antijurídica ${ }^{41}$. En este sentido, se sostuvo que existiendo un interés social comprometido, la obtención y divulgación de información se

A modo de ejemplo, ver: CPLT. Resolución de 15 de julio de 2010. Rol C-193-2010, considerandos 6 y 8.

A modo de ejemplo, ver: CPLT. Resolución de 22 de septiembre de 2009. Rol A-115-09, considerando 11.

Artículo 161-A Código Penal. "Se castigará con la pena de reclusión menor en cualquiera de sus grados y multa de 50 a 500 Unidades Tributarias Mensuales al que, en recintos particulares o lugares que no sean de libre acceso al público, sin autorización del afectado y por cualquier medio, capte, intercepte, grabe o reproduzca conversaciones o comunicaciones de carácter privado; sustraiga, fotografíe, fotocopie o reproduzca documentos o instrumentos de carácter privado; o capte, grabe, filme o fotografíe imágenes o hechos de carácter privado que se produzcan, realicen, ocurran o existan en recintos particulares o lugares que no sean de libre acceso al público. Igual pena se aplicará a quien difunda las conversaciones, comunicaciones, documentos, instrumentos, imágenes y hechos a que se refiere el inciso anterior. En caso de ser una misma la persona que los haya obtenido y divulgado, se aplicarán a ésta las penas de reclusión menor en su grado máximo y multa de 100 a 500 Unidades Tributarias Mensuales. Esta disposición no es aplicable a aquellas personas que, en virtud de ley o de autorización judicial, estén o sean autorizadas para ejecutar las acciones descritas". 
habría encontrado plenamente justificada.

\subsection{Bien jurídico y sus límites}

Uno de los aspectos más interesantes del caso es que la Corte Suprema -más allá de realizar un análisis del tipo penal-, optó por pronunciarse derechamente sobre los límites del bien jurídico protegido por artículo 161-A del Código Penal, esto es, la intimidad, tanto en su dimensión individual como familiar"2. Sobre el particular señaló que "[...] el carácter privado de una conversación no está reservado a todo aquello que el titular otorgue esa denominación, porque podría llegarse a extremos de subjetivización en que carecería de toda certeza la conducta [...] Sí puede afirmarse que el carácter privado desaparece cuando se trata de conductas que revisten un interés público ${ }^{\prime 43}$. Asimismo, en la sentencia de reemplazo, recoge la jurisprudencia del Tribunal Constitucional Español, respecto a que en el secreto de las comunicaciones privadas "[...] la norma constitucional se dirige inequívocamente a garantizar su impenetrabilidad frente a terceros ajenos a la comunicación misma, mas no se configura respecto de quienes participaron directamente en ella" 44 .

En otras palabras, la Corte Suprema señaló que la privacidad del contenido de una conversación no depende de lo que una de las partes entienda por privado, ya que de otro modo el límite del derecho a la intimidad dependería de la mera subjetividad de cada persona. Asimismo, se reconoce expresamente el interés público como límite al derecho a la intimidad.

\subsection{Concepto de interés público}

Junto con definir el alcance del bien jurídico protegido y sus límites, la Corte Suprema -al realizar las consideraciones sobre qué debe entenderse por interés público- no establece una definición exacta, pero desarrolló diversos elementos que configuran una noción amplia de interés público.

En la sentencia de casación se resolvió que:

[...] en el caso de análisis si bien no se ha demostrado la comisión de un ilícito por los presuntos perjudicados, lo cierto es que su conducta importa al menos una transgresión a la ética por parte de profesionales de la salud que otorgaban licencias médicas falsas en desmedro de los demás cotizantes de los sistemas de salud, cuestión que reviste un interés público con mérito suficiente para ser socializada, lo que permitirá en último término, el fin de una situación reprochable e inconveniente. Como advierte el recurso, no ha podido estimarse que la conversación de los periodistas con la profesional sea de carácter privado, pues se refiere a hechos que revelan irregularidades de la praxis médica verificables para ante la opinión pública ${ }^{45}$.

Asimismo, la sentencia de reemplazo dispuso:

[...] a mayor abundamiento, la decisión tomada por una profesional de la salud que accede sin ningún cuestionamiento a la realización de un hecho que eventualmente puede conducir a un fraude al sistema de salud, debe aceptar el riesgo de que su conversación pueda ser reproducida posteriormente a terceras personas, o incluso, ante la opinión pública, dado el interés

\footnotetext{
42 GARRIDO, Mario. Derecho Penal... op.cit, p. 436.

43 Corte Suprema de Chile. Sentencia de casación de 21 de agosto 2013, op.cit, 5.

44 Tribunal Constitucional de España. Sentencia del 29 de noviembre de 1984. Rol STC 114-1984.

45 Corte Suprema de Chile. Sentencia de casación de 21 de agosto 2013, op.cit, considerando 5.
} 
público comprometido, como aconteció en los hechos ${ }^{46}$.

De la mera lectura de estos considerandos se pueden apreciar algunos elementos relevantes para la configuración de una noción de interés público. En primer lugar, se aprecia que la Corte Suprema sostiene que existe interés público aun cuando no se establece que los médicos sean funcionarios públicos. En este sentido, aunque se trate de conductas de profesionales del sector privado, para la Corte Suprema puede existir una relevancia pública en conocer la información.

Asimismo, el máximo tribunal establece que se verifica un interés público en divulgar la información obtenida, incluso cuando el eventual fraude no se esté haciendo directamente al patrimonio fiscal, ya que indica que la víctima de las irregularidades relacionadas con las licencias médicas no es el Estado, sino el resto de los cotizantes del sistema de salud.

Por otra parte, respecto a la conducta denunciada -emisión fraudulenta de licencias médicasla Corte Suprema estima que no es necesaria la comisión de un delito para poder verificar la presencia del interés social en el caso, sino que basta la transgresión ética de los profesionales en el desempeño de sus funciones para que dicha conducta pueda ser conocida por la sociedad.

En el fallo del caso Cordero con Lara y otros, la Corte Suprema chilena por primera vez reconoce al interés público como criterio válido para restringir el derecho a la privacidad, siguiendo la tendencia de la jurisprudencia internacional de los organismos de protección internacional. Incluso, la Corte Suprema chilena va más allá y amplía la noción de interés público que la Corte IDH desarrolló en el caso Mémoli vs. Argentina. Como señalamos precedentemente, la Corte IDH en dicho caso matizó su jurisprudencia constante, indicando que cuando se trata de denuncias de irregularidades, donde las víctimas de la supuesta estafa son los miembros de una organización privada -en el caso sub lite, la Asociación Mutual Italiana- no se verificaba interés público en el caso. La Corte IDH consideró expresamente que no existía relevancia pública en proteger las denuncias de los señores Mémoli contra los directivos de la Mutual, toda vez que las acusaciones habían sido desechadas por instancias administrativas y judiciales ${ }^{47}$.

De manera diversa, la Corte Suprema de Chile estimó que, pese a que la información no guardaba relación directa con el funcionamiento del Estado, la mera ocurrencia de una falta a la ética profesional por parte de la psiquiatra entrañaba un interés público comprometido en la divulgación de la información, sin tomar en consideración en la sentencia el hecho de que -al igual que los directivos de la Mutual en el caso Mémoli-, la médico denunciada había sido absuelta de la acusación del delito de fraude previsional por la Corte de Apelaciones de Santiago varios años antes. En este sentido, la Corte chilena establece un criterio respecto a qué se entiende por interés público, que es más amplio que el de la jurisprudencia reciente de la Corte IDH. En efecto, la Corte Suprema en este caso protege ampliamente la necesidad de transparentar actos contrarios a la ética como un asunto de interés público.

Las consecuencias de la decisión de la Corte Suprema van a causar impacto, tanto en el ejercicio fiscalizador de la prensa, como en el control ciudadano que se hace a través de los mecanismos de transparencia y acceso a la información, en relación a la forma en que el Estado y los particulares se desenvuelven ante la sociedad. En un país democrático, aun cuando deben existir adecuados mecanismos de control por parte de las autoridades, no hay mejor fiscalización que la que realizan los propios ciudadanos. No debemos olvidar la máxima según la cual "mientras más estrictamente nos observan, mejor nos comportamos" ${ }^{48}$.

\footnotetext{
46 Corte Suprema de Chile. Sentencia de reemplazo de 21 de agosto 2013, op.cit, considerando 3.

47 Corte IDH. Caso Mémoli vs. Argentina, op.cit, párrs. 146, 147 y 148.

48

La cita original corresponde a "The more strictly we are watched, the better we behave". BENTHAM, Jeremy.
} 


\section{Conclusiones}

En la jurisprudencia chilena, tradicionalmente el derecho a la privacidad fue amparado de manera irrestricta por sobre el derecho de acceder a la información y difundirla. Pese a que a nivel comparado hace varias décadas se venía desarrollando el concepto de interés público en tribunales extranjeros e internacionales como límite del derecho a la privacidad, en Chile este criterio no era considerado por la jurisprudencia en la ponderación de los conflictos entre el derecho fundamental a la intimidad y los derechos de la información. Esta tendencia se revirtió en agosto de 2013, con la resolución de la Corte Suprema del caso Cordero con Lara y otros, en la cual se reconoció la importancia de la información para la sociedad y que se justifica una limitación al derecho a la privacidad, cuando se verifica que los datos en cuestión son relevantes para la ciudadanía.

En este caso la Corte Suprema no solo acogió el concepto de interés público, sino que también amplió el contenido que le ha dado la Corte IDH en el caso Mémoli vs. Argentina, al entender que este se encuentra presente en las actuaciones de funcionarios públicos o en la comisión de delitos criminales, pero también en aquellos hechos, cometidos por particulares, que pudieran afectar intereses de carácter general y que comprometen la ética con que se desarrollan las actividades.

De esta forma, este fallo se convierte en un gran avance para la conceptualización del interés público en la jurisprudencia nacional, y para la consolidación de una cultura de transparencia y control por parte de la ciudadanía de las actividades fundamentales para la sociedad.

Recibido: 11 de noviembre de 2013

Aceptado: 28 de febrero de 2014

Unpublished, from manuscripts in the Library of the University College of London. The Bentham Project, $2010, \mathrm{p}$.

1. Disponible [en línea] <http://www.ucl.ac.uk/Bentham-Project/publications/benthampanopticon.pdf > [consulta:

31 octubre 2013]. 
